Board of Governors of the Federal Reserve System

International Finance Discussion Papers

Number 1025

August 2011

\title{
Evaluating the Forecasting Performance of Commodity Futures Prices
}

Trevor A. Reeve and Robert J. Vigfusson

NOTE: International Finance Discussion Papers are preliminary materials circulated to stimulate discussion and critical comment. References in publications to International Finance Discussion Papers (other than an acknowledgment that the writer has had access to unpublished material) should be cleared with the author or authors. Recent IFDPs are available on the Web at www.federalreserve.gov/pubs/ifdp/. This paper can be downloaded without charge from Social Science Research Network electronic library at http://www.ssrn.com/. 


\title{
Evaluating the Forecasting Performance of Commodity Futures Prices
}

\author{
Trevor A Reeve and Robert J. Vigfusson*† \\ Board of Governors of the Federal Reserve System
}

\begin{abstract}
Commodity futures prices are frequently criticized as being uninformative for forecasting purposes because (1) they seem to do no better than a random walk or an extrapolation of recent trends and (2) futures prices for commodities often trace out a relatively flat trajectory even though global demand is steadily increasing. In this paper, we attempt to shed light on these concerns by discussing the theoretical relationship between spot and futures prices for commodities and by evaluating the empirical forecasting performance of futures prices relative to some alternative benchmarks. The key results of our analysis are that futures prices have generally outperformed a random walk forecast, but not by a large margin, while both futures and a random walk noticeably outperform a simple extrapolation of recent trends (a random walk with drift). Importantly, however, futures prices, on average, outperform a random walk by a considerable margin when there is a sizeable difference between spot and futures prices.
\end{abstract}

Keywords: financial markets, forecasting, commodities

JEL classifications: G13, E37, Q47

\footnotetext{
${ }^{*}$ The views in this paper are solely the responsibility of the authors and should not be interpreted as reflecting the views of the Board of Governors of the Federal Reserve System, any other person associated with the Federal Reserve System.

${ }^{\dagger}$ Comments and suggestions can be directed to robert.j.vigfusson@frb.gov.
} 


\section{Introduction}

Commodity futures prices are frequently criticized as being uninformative for forecasting purposes because (1) they seem to do no better than a random walk (Alquist et al., 2011) or an extrapolation of recent trends and (2) futures prices for commodities often trace out a relatively flat trajectory even though global demand is steadily increasing. In this paper, we attempt to shed light on these concerns by discussing the theoretical relationship between spot and futures prices for commodities and by evaluating the empirical forecasting performance of futures prices relative to some alternative benchmarks.

The key results of our analysis are:

- When commodities are storable, spot prices reflect both current supply and demand conditions as well as expectations for those conditions in the future because market participants can arbitrage between the current spot price and the futures price. Accordingly, relatively flat futures paths are neither surprising nor an indication of dysfunction on the part of futures markets: For any given expected price in the future, market participants will adjust their positions so that the expected difference between the price now and the price in the future will approximate market rates of return (adjusted for costs of storing or selling commodities).

- Futures prices have generally outperformed a random walk forecast, but not by a large margin, while both futures and a random walk noticeably outperform a simple extrapolation of recent trends (a random walk with drift). Importantly, however, futures prices outperform a random walk by a considerable margin when there is a sizeable difference between spot and futures prices.

These results suggest that futures prices remain a reasonable guide for forecasting commodity prices. However, as we will discuss, futures prices may also, in principle, contain a risk premium that creates a wedge between the observed futures price and the spot price expected to prevail in the future. In the final section of this note, we attempt to identify such a risk premium. Our results suggest that controlling for a risk premium in real time does not materially improve the forecasting performance of futures prices.

There is a large literature on evaluating the forecasting performance of futures markets. In addition to classic articles such as Fama and French (1987), more recent contributions include Moosa and Al-Loughani (1994), Chin et. al. (2005), and Alquist and Kilian (2010). As we will discuss below, given variations in both the commodities and time periods that have been evaluated, the literature has not reached a consensus. Compared with these other papers, our discussion of the forecasting performance conditional on the difference between spot and futures prices is novel. 


\section{The Relationship Between Spot and Futures Prices for Commodities}

Expectations of future commodity prices are a critical determinant of spot prices, and this linkage depends on the capacity to store commodities in inventory. Transactions in the spot market require the seller to accept that the price received is adequate compensation for forgoing the opportunity to hold the commodity in inventory to sell later. (For producers of commodities, a similar calculation applies to the decision to produce an extra unit of the commodity today versus in the future.) Likewise, the buyer must accept that the benefit of purchasing now outweighs the benefits of waiting to buy later. Accordingly, the spot price embodies an expectation of what prices will be in the future. As a corollary, changes in expectations of future supply and demand conditions will show up as movements in both current spot and futures prices.

The relationship between spot and futures prices can be derived from conditions that rule out profitable arbitrage opportunities, so that holders of commodities are indifferent between selling them in the spot market or holding them in inventory to deliver later at the contracted futures price. ${ }^{1}$ To illustrate, denote the current spot price as $S$ and the current value of the one-year ahead futures price as $F$, and consider the following cases:

- Case 1: Suppose that the spot price is above the futures price $(S>F)$. Here the arbitrage opportunity would be to sell out of inventory today at the spot price $S$, put the money in an interest bearing instrument (earning interest $R$ ), and use a futures contract to restock the inventory a year from now at the guaranteed price of $F$. Such a strategy also has the benefit of reducing the storage costs that must be paid to carry inventories (denoted $C$ ), which include both warehousing costs and, for some commodities, product depreciation and/or spoilage. But keeping a commodity in stock has its own additional value, which is often called the convenience yield (denoted $Y$ ), which must be foregone under this strategy. Thus, to rule out a profitable arbitrage opportunity, it must be that the benefits of the strategy, $(1+R+C) S$, are less than or equal to the costs, $F+Y S$, or $(1+R+C-Y) S \leq F .^{2}$

- Case 2: Suppose that the spot price is below the futures price $(S<F)$. The attempted arbitrage would be to borrow money (at interest rate $R$ ) to buy one unit of the good at spot price $S$ and then deliver it a year later at the already assured price $F$. In holding the good, one pays the storage costs $C$ but also receives the associated convenience yield $Y$. Therefore, to prevent an arbitrage opportunity, we require that the total costs of this strategy, $(1+R+C) S$, be greater than or equal to the benefits, $F+Y S$, that is, $(1+R+C-Y) S \geq F$.

\footnotetext{
${ }^{1}$ Developments of these relationships can be found in standard textbooks including Hull (2002) and also in articles such as Pindyck (2001).

${ }^{2}$ In this example, the storage cost $\mathrm{C}$ and convenience yield $\mathrm{Y}$ are assumed to be proportionate to the price of the commodity S. Alternatively, we could have specified the cost in per physical unit terms, so $(1+\mathrm{R}) \mathrm{S}+\mathrm{C}-\mathrm{Y} \leq \mathrm{F}$.
} 
Combining these two conditions gives $F=(1+R+C-Y) S$ or, equivalently, $F / S=$ $(1+R+C-Y)$. As the storage costs $(C)$ and the convenience yield $(Y)$ tend towards zero, the difference between the spot and futures prices converge to the rate of interest. This convergence is equivalent to the familiar Hotelling's rule that spot commodity prices will rise at the discount rate, that is, $F=(1+R) S$. In this case, the futures-based forecast is similar to a random walk forecast when interest rates are low. In contrast, the higher the storage costs and convenience yield, the more the futures price can differ from the spot price for any given interest rate.

The costs for storing a commodity should be a function of the level of inventories and the physical properties of the commodity. When inventories are very high and approaching storage capacity limits, the cost of additional storage $(C)$ should also be high. For example, in the fall of 2008, conventional oil storage facilities were near capacity and, so, oil was stored in tanker ships, even though ship-based storage is much more expensive than land-based storage. These high storage costs allowed the difference between the spot price and the futures price to widen. In December of 2008, the spot price for oil was around $\$ 40$ barrel and the twelve-month ahead futures price was above $\$ 55$ per barrel.

In addition, storage costs also vary across commodities. For example, the storage costs for fresh cut flowers can be thought of as approaching infinity, which would be sufficient to break the link between the futures and spot prices. In such a market, inventories cannot be used to smooth prices. In contrast, other commodities such as metals have relatively low storage costs. For these commodities, inventory smoothing limits the extent that future prices can differ from spot prices.

Whereas inventory accumulation becomes more costly as inventories near capacity, the convenience yield $(Y)$ of having an additional unit of stock is particularly high when inventories are low. For example, one might require the good to keep a production process running or avoid disappointing customers. As such, increases in the convenience yield may at times drive the spot price well above the futures price.

How well do these theoretical results conform with the observed structure of futures prices? Table 1 reports statistics on the distribution of the ratio of the one-year ahead futures price to the spot price $(F / S)$ for a selection of commodities from 1990 through $2010{ }^{3}$ The values in column iii show the percent of the time that the futures price was within $+/-5$ percent of the spot price $(0.95<F / S<1.05)$. By this score, copper ranks fairly high, with the futures price within 5 percent of the spot price 45 percent of the time. Towards the other extreme is natural gas, for which the futures price was within 5 percent of the spot price only 24 percent of the time. Crude oil, at 29 percent, is in between these extremes. The fraction of the time futures exceeded spot prices by more than 15 percent $(F / S>1.15$, shown in column v) was essentially zero for many metals, 6 percent for oil, and 28 percent for natural gas.

These distributions accord well with reported storage costs. For example, storage

\footnotetext{
${ }^{3}$ Because not all futures markets have contracts for every month, defining the year-ahead futures price is not straightforward. To maximize our sample, in this memo we use 12-month ahead futures for energy, 8-month ahead futures for agricultural commodities, and 15-month ahead forwards for metals.
} 
capacity for metals is virtually unlimited, as all that is required is a warehouse to protect stocks from the elements, vandals, and thieves. ${ }^{4}$ Within the metals category, given that storage costs per pound are similar for the various metals, the high average price of nickel per pound and correspondingly low storage costs per unit value likely helps explain why its futures price was within 5 percent of the spot 73 percent of the time, the greatest percentage amongst the metals. Conversely, natural gas is notoriously difficult and dangerous to store, requiring specialized equipment or suitable underground caverns. And crude oil, which is typically stored in tanks, is between these extremes. Additionally, agricultural commodities, which can spoil, tend to have a wider distribution of $F / S$ than more durable commodities such as metals.

Figure 1 plots the observed values of $F / S$ for copper (on the vertical axis) against the level of inventories (on the horizontal axis). Consistent with the previously described results, when inventories of copper have reached unusually high levels, the futures price has remained close to the spot price; storage costs for copper do not rise sharply with inventory levels and the convenience yield of holding copper is depressed by ample stocks. As inventories get very low (and the convenience yield of having copper on hand rises), futures prices can lie well below spot prices. Historically, however, futures prices for copper have not tended to fall below 75 percent of the spot price.

Figure 2 shows a similar plot for crude oil. In contrast to copper, when oil inventories get large, storage capacity constraints begin to bind and the marginal cost of storage rises, resulting in futures prices lying well above spot prices. At low levels of inventories, however, the pattern, as expected, is more similar to copper, with futures prices lying well below spot prices.

To sum up, flat futures profiles for commodities are common when inventories are within typical ranges. The reason for this is that arbitrage across the futures curve ensures that spot prices incorporate information about future supply and demand conditions. When inventories are particularly low or high, however, the costs associated with arbitraging commodities over time are large, and futures prices can differ markedly from spot prices.

\section{Forecasting Performance of Futures Prices}

In this section, we compare the forecasting performance of futures-based forecasts with two alternatives: a random walk (where the forecasted value is the current spot price) and a random walk with drift (where the forecasted value rises in line with recent experience). We also present results showing that futures-based forecasts tend to outperform random

\footnotetext{
${ }^{4}$ For metals, the London Metals Exchange reports maximum daily warehouse storage rates of roughly 40 cents per ton, which at current commodity prices would amount to roughly 1.6 percent a year for copper, 0.7 percent a year for nickel, and 6.5 percent a year for zinc. (These rates vary somewhat by metal and by location.) Warehouses can and do offer discounts to preferred customers. Additional charges are associated with removing the metals from the warehouses, which can be a substantial source of revenue for the warehouses.
} 
walk forecasts by the largest margin when the forecasts are most divergent, that is, when futures prices differ the most from spot prices.

Our accuracy measure is the mean squared error (MSE) of the forecast. Futuresbased forecasts are compared to the alternatives by examining the relative MSE, that is, the ratio of the MSE for the futures forecast to the MSE of the alternative. When the relative MSE equals 1, the forecast performance of the two methods is equivalent. When the relative MSE is less than one, futures dominate the alternative, and when it is greater than one, the alternative dominates futures.

Table 2 reports the relative MSEs for futures versus the random walk for two forecast horizons ( 3 months, and a year-ahead ${ }^{5}$ ) over two sample periods (1990 to 2010 and 2003 to 2010). As shown in the table, the relative MSEs are generally below 1 for the full sample, indicating that futures-based forecasts have outperformed a random walk over this period. For the 2003 to 2010 sample, however, the results are more mixed, with neither futures nor the random walk clearly dominating.

To shed light on the changing forecasting performance of these methods over time, Figure 3 shows the evolution of relative MSEs over 8-year moving windows for copper, corn, and crude oil. As the figure makes clear, futures consistently outperformed the random walk for all three commodities prior to the early 2000s and have continued to do so for corn. During the latter half of the 2000s, in contrast, a random walk outperformed futures for copper and oil. Most recently, however, futures and a random walk look about the same for oil.

The second alternative to a futures-based forecast is a random walk with drift, in which prices are projected to rise or fall at a rate comparable to that observed in the recent past. Such an approach would be consistent with arguments that commodity prices will continue to rise in line with global demand, thus extending recent trends. Table 3 reports relative MSEs for futures-based forecasts versus such a model where the drift term is assumed to be the average growth rate over the past year. As can be seen in the table, this model does very poorly when evaluated over the whole sample or just the observations since 2003.

Although futures do have a better record than a random walk over the entire sample, the improvement does not appear to be substantial. This result should not be terribly surprising in light of the discussion in the previous section. The storability of commodities and the elimination of arbitrage opportunities implies that spot and futures prices are linked. With modest storage costs and sufficient inventories to keep convenience yields low, we should expect the futures-based forecasts and random walk forecasts to be broadly similar.

That being said, there are times, as noted above, when futures prices can differ markedly from spot prices. When the futures price and the spot price differ, the futures price should in principle be more informative for forecasting prices relative to a random walk. Prices will differ when there are temporary factors that result in sharp inventory builds or declines. In these periods, the futures price should, in theory, look through

\footnotetext{
${ }^{5}$ With the year-ahead as defined in Footnote 3.
} 
these developments and, thus, produce a better forecast.

Figure 4 examines this proposition for oil prices. The figure plots the ratio of the one-year ahead futures price to the spot price. The blue dots denote the times when the futures-based forecast outperformed the random walk, and the red dots show the times when the random walk outperformed futures. It is evident that when the crude oil futures price is materially above the spot price (the upper range of the graph), futures have done a better job of forecasting prices in the vast majority of the cases.

When the futures price is below the spot price, the evidence is somewhat more mixed. In the 1990s, the futures price generally did better. However, between 2003 and 2005, the futures price generally did worse as the market mistook the permanent shift in oil prices for a temporary increase that would soon be reversed. Market participants did not fully appreciate the persistence of the shocks hitting commodity prices and expected commodity prices to moderate. Thus, in this period, the spot price proved to be a better predictor than the futures prices.

More systematically, Table 4 reports the relative MSEs for futures versus a random walk for a range of commodities as a function of the futures-spot relationship. For crude oil, the relative MSE is close to 1 when futures are within 5 percent of the spot price (column iii). But when futures are more than 5 percent above spot prices (columns iv and $\mathrm{v}$ ), the relative forecasting performance of futures prices rises markedly. Although the results of this exercise vary considerably across commodities, the overall evidence suggests that futures are more informative the greater their divergence from spot prices.

\section{Risk Premiums}

The previous results suggest that futures prices remain a reasonable guide for forecasting commodity prices, at least relative to some basic alternatives. However, futures prices, in principle, could also contain a risk premium that creates a wedge between the observed futures price and the underlying expected future spot price. If such a risk premium can be identified in commodity futures prices, then controlling for it when making forecasts should improve accuracy.

To think about the risk premium, it is useful to consider three classes of futures market participants. The first class is producers of commodities whose incomes depend positively on commodity prices and who, therefore, would want to insure against price declines by selling (i.e. go short) in the futures markets. The second class is users of commodities whose incomes depend negatively on prices and who, therefore, would want to insure against price increases by buying (i.e. go long) in the futures markets. The third class is made up of market participants whose incomes neither increase nor decrease appreciably with commodity prices. This group (who could be defined as speculators) serves to balance the market by providing the net supply of insurance services to the other participants; that is, they fill the gap between buyers and sellers in the futures markets. The risk premium is the compensation given to the speculators to entice them to participate in these markets. 
To illustrate the roles of the first two kinds of market participants, Figure 5 reports data from the U.S. Commodity Futures Trading Commission (CFTC) on the net long positions of producers/users as a fraction of open interest for eight commodities traded on U.S. futures markets. (The available public data only reports this aggregate category which includes producers, merchants, processors and users.) The following patterns are clear. For almost all categories, the producers/users are net short. Thus, it seems that the demand from producers to be insured against falling prices outweighs the demand from users to be insured against higher prices. For energy commodities, the net long positions of producers/users are relatively close to zero. Producers/users are almost always net short for agricultural commodities, but there can be some fairly large swings in the magnitude of these positions. Given these net short positions, speculators will have to go net long to balance the market. As such, holding everything else equal, we should expect the average risk premium to be positive and larger for agricultural commodities than for oil. By a positive risk premium, we mean that we should expect the futures price to be less than expected spot price, so that going net long - that is, contracting to buy commodities at the futures prices - is a profitable activity for the speculators. However, we should note that competition amongst speculators should serve to decrease the profitability of providing insurance to producers. ${ }^{6}$

To test for risk premiums, we follow the literature in estimating forecast efficiency regressions, ${ }^{7}$ which are defined as

$$
S_{t+k}-S_{t}=\alpha+\beta\left(F_{t, t+k}-S_{t}\right)+v_{t+k}
$$

In these regressions, the dependent variable is the error from a random-walk forecast, and the independent variable is the difference between the forecasted price from futures markets and that from a random walk. There are four tests of interest: the three individual tests of whether $\alpha=0, \beta=0$, and $\beta=1$ and the joint test of $\alpha=0$ and $\beta=1$. If $\alpha=0$ and $\beta=1$ then futures are an unbiased predictor of the spot price and there is no identifiable risk premium. If the difference between the estimated constant $\alpha$ and zero is statistically significant, then there is evidence of a constant risk premium. If the difference between the estimated slope coefficient $\beta$ and 1 is statistically significant, then the risk premium varies over time according to the tilt in the futures curve. Additionally, if the slope coefficient $\beta$ is significantly different from zero, then futures prices have explanatory power for the forecast error from a random walk. Thus, this regression provides an alternative method for comparing random walk and futures-based forecasts.

\footnotetext{
${ }^{6} \mathrm{An}$ additional constraint on the risk premium is that commodity producers and users have the alternative of hedging by adjusting their inventory positions. If a user wants to guarantee his price, then he could buy the product today and just hold it in inventory. Likewise, if a producer wants to insure the price received, he could either sell out of existing inventory or else speed up extraction (which, in the near term, may be more feasible for metals than for agricultural goods). Hence, the cost of using futures to hedge (the risk premium) should not be much larger than the costs of hedging through physical holdings.

${ }^{7}$ See the discussion in Chernenko et al (2004) and Chinn et al. (2005).
} 
Table 5 reports the results of these hypothesis tests for the one-year ahead forecasts over the 1990 to 2010 sample period. Column (i) reports the point estimates of the intercept term $\alpha$. As indicated by column (ii), for most commodities, we fail to reject the null hypothesis that $\alpha=0$ at the 95 percent critical value, meaning that there does not appear to be a constant risk premium that is statistically significant. The point estimates for the slope coefficient $\beta$ are reported in column (iii). For nearly half of the commodities, we can reject the hypothesis that the slope coefficient equals 0 , suggesting that there is useful information in the futures. Although we fail to reject for most commodities the hypothesis that the slope coefficient equals one (column v), the point estimates can be quite different from one, suggesting that the risk premium varies with the shape of the futures curve. As reported in the final column of the table, we get four rejections (zinc, cotton, live cattle and wheat) for the joint hypothesis that $\alpha=0$ and $\beta=1$ suggesting some bias and the presence of a risk premium.

Because the estimated $\beta$ coefficients for many commodities are less than one, it is possible that forecasting performance could be improved by attenuating the slope of the futures curve somewhat, which is equivalent to controlling for a variable risk premium. However, making such corrections in real time is not so simple. We can only estimate the values of $\alpha$ and $\beta$ using the data that was available when the forecast would have been made. In order to allow for structural breaks, the values of $\alpha$ and $\beta$ were estimated over a rolling sample of 30 monthly observations. As reported in Table 6 , forecasts based on these real-time estimates do not perform better than the simple, unadjusted futures-based forecast over the 2003-2010 sample. The reason for this outcome is that the values of $\alpha$ and $\beta$ are not stable over time and hence using estimated values results in poor predictors for subsequent periods. The only exception is a slight improvement for natural gas at the three-month horizon.

\section{Conclusions}

Our main conclusions are the following:

- When commodities are storable, spot prices reflect both current supply and demand conditions as well as expectations for those conditions in the future because market participants can arbitrage between the current spot price and the futures price. Accordingly, relatively flat futures paths are neither surprising nor an indication of dysfunction on the part of futures markets: For any given expected price in the future, market participants will adjust their positions so that the expected difference between the price now and the price in the future will approximate market rates of return (adjusted for costs of storing or selling commodities).

- Futures prices have generally outperformed a random walk forecast, but not by a large margin, while both futures and a random walk noticeably outperform a simple extrapolation of recent trends (a random walk with drift). Importantly, however, 
futures prices have on average outperformed a random walk by a considerable margin when there is a sizeable difference between spot and futures prices.

These results suggest that futures prices remain a reasonable guide for forecasting commodity prices. Although, in principle, futures prices may also contain a risk premium,

we find that controlling for a risk premium in real time does not materially improve the forecasting performance of futures prices.

\section{References}

Alquist, Ron and Lutz Kilian, 2010, "What Do We Learn from the Price of Crude Oil Futures?" Journal of Applied Econometrics 25(4).

Alquist Ron, Lutz Kilian and Robert J. Vigfusson, 2011, "Forecasting the Price of Oil," International Finance Discussion Paper No. 1022, Board of Governors of the Federal Reserve System.

Chernenko Sergey V., Krista B. Schwarz and Jonathan H. Wright 2004, "The Information Content of Forward and Futures Prices: Market Expectations and the Price of Risk," International Finance Discussion Paper No. 808, Board of Governors of the Federal Reserve System.

Chinn, Menzie D., Olivier Coibion, and Michael LeBlanc, 2005, "The Predictive Content of Energy Futures: An Update on Petroleum, Natural Gas, Heating Oil and Gasoline Markets," NBER Working Paper No. 11033 (January).

Fama, Eugene F. and Kenneth R. French, 1987, "Commodity Futures Prices: Some Evidence on Forecast Power, Premiums, and the Theory of Storage," The Journal of Business, 60(1) 55-73.

Hull, John C. 2002 Options, Futures, and Other Derivatives Prentice Hall; 5 edition.

Moosa, Imad and Nabeel Al-Loughani, 1994, "Unbiasedness and time varying risk premia in the crude oil futures market," Energy Economics 16(2), pp. 99-105.

Pindyck, Robert S., 2001, "The Dynamics of Commodity Spot and Futures Markets: A Primer," Energy Journal 22(3): 1-29. 
Table 1 Distribution of the Slope of Futures Relative to Spot Prices (Percent)

$\mathrm{F} / \mathrm{S}$

$\begin{array}{ccccc}<0.85 & (0.85 \text { to } 0.95) & (0.95 \text { to } 1.05) & (1.05 \text { to } 1.15) & >1.15 \\ \text { (i) } & \text { (ii) } & \text { (iii) } & \text { (iv) } & \text { (v) }\end{array}$

Energy

Crude Oil

$16 \quad 31$

29

39

19

6

Natural Gas

$10 \quad 25$

24

18

7

Metals

Aluminum

12

16

20

28

Copper

0

Lead

Nickel

5

\section{2}

17

18

11

\section{8}

45

58

27

50

22

73

13

43

Tin

6

12

10

22

46

41

20

Agricultural

Corn

Cotton

3

$\begin{array}{ll}3 & 7\end{array}$

23

26

27

Coffee

10

9

28

30

30

50

45

Soybeans

2

46

37

19

20

19

Notes: For commodities in the energy category, statistics are calculated for 12-month ahead futures. For metals, the statistics are for 15-month ahead forwards. For agricultural commodities, the statistics are for 8-month ahead futures. Samples begin in 1985 or as available. 
Table 2 : Relative Mean Squared Error of Futures Based Forecasts to Random Walk

\begin{tabular}{|c|c|c|c|c|}
\hline \multirow{3}{*}{ Sample } & \multicolumn{2}{|c|}{ Three Months Ahead } & \multicolumn{2}{|c|}{ A Year Ahead $\dagger$} \\
\hline & $1990-2010$ & 2003-2010 & $1990-2010 \mathrm{e}$ & 2003-2010 \\
\hline & (i) & (ii) & (iii) & (iv) \\
\hline \multicolumn{5}{|l|}{ Energy } \\
\hline Crude Oil & 0.94 & 0.93 & 0.92 & 0.98 \\
\hline Heating Oil & 0.96 & 1.01 & 0.92 & 1.03 \\
\hline Natural Gas & $0.88^{*}$ & 0.92 & $0.86^{*}$ & 0.94 \\
\hline \multicolumn{5}{|l|}{ Metals } \\
\hline Aluminum & 1.00 & 0.99 & 0.93 & 0.95 \\
\hline Copper & 1.00 & 1.02 & 1.08 & 1.20 \\
\hline Lead & 0.98 & 1.01 & 1.00 & 1.05 \\
\hline Nickel & 1.00 & 1.01 & 1.00 & 1.05 \\
\hline Tin & 1.00 & 1.00 & 1.05 & 1.04 \\
\hline Zinc & 0.93 & 0.96 & 0.86 & 0.90 \\
\hline \multicolumn{5}{|c|}{ Agricultural } \\
\hline Corn & 0.91 & 0.92 & 0.77 & 0.71 \\
\hline Cotton & 0.96 & 1.04 & 0.97 & 0.93 \\
\hline Coffee & 1.00 & 0.91 & 0.93 & 0.92 \\
\hline Live Cattle & $0.75^{*}$ & $0.76^{*}$ & 1.59 & 1.63 \\
\hline Soybeans & 0.88 & 0.84 & 0.84 & 0.81 \\
\hline Wheat & 0.98 & 0.91 & 1.05 & 0.93 \\
\hline
\end{tabular}

Notes: $\dagger$ The year ahead forecast is based on the appropriate and available futures contract. For commodities in the energy category, statistics are calculated for 12-month ahead futures. For metals, the statistics are for 15-month ahead forwards. For agricultural commodities, the statistics are for 8-month ahead futures. Samples begin in 1990 or as available.

* Indicates a statistically significant difference based on a Diebold-Mariano test. 
Table 3 : Relative Mean Squared Error of Futures Based Forecasts to Random Walk With Drift Three Months Ahead

\begin{tabular}{|c|c|c|c|c|}
\hline Sample & $\begin{array}{l}1990-2010 \\
\text { (i) }\end{array}$ & $\begin{array}{l}2003-2010 \\
\text { (ii) }\end{array}$ & $\begin{array}{c}1990-2010 \text { e } \\
\text { (iii) }\end{array}$ & $\begin{array}{c}2003-2010 \\
\text { (iv) }\end{array}$ \\
\hline \multicolumn{5}{|l|}{ Energy } \\
\hline Crude Oil & $0.74^{*}$ & 0.64 & $0.36^{*}$ & $0.34 *$ \\
\hline Heating Oil & $0.78^{*}$ & 0.72 & $0.38 *$ & $0.39 *$ \\
\hline Natural Gas & $0.69 *$ & $0.68 *$ & $0.30 *$ & $0.35 *$ \\
\hline \multicolumn{5}{|l|}{ Metals } \\
\hline Aluminum & 0.74 & 0.74 & 0.57 & 0.63 \\
\hline Copper & 0.83 & 0.86 & 0.71 & 0.86 \\
\hline Lead & 0.77 & 0.76 & 0.58 & 0.62 \\
\hline Nickel & 0.80 & 0.83 & 0.43 & 0.46 \\
\hline Tin & 0.85 & 0.88 & 0.56 & 0.55 \\
\hline Zinc & 0.77 & 0.82 & 0.40 & 0.39 \\
\hline \multicolumn{5}{|l|}{ Agricultural } \\
\hline Corn & $0.69 *$ & $0.71 *$ & $0.41 *$ & $0.43 *$ \\
\hline Cotton & $0.78^{*}$ & 0.89 & $0.49 *$ & 0.55 \\
\hline Coffee & $0.77^{*}$ & $0.70^{*}$ & $0.56^{*}$ & 0.57 \\
\hline Live Cattle & $0.61 *$ & $0.63 *$ & 0.73 & 0.74 \\
\hline Soybeans & $0.67 *$ & $0.63 *$ & $0.47 *$ & $0.45^{*}$ \\
\hline Wheat & $0.76^{*}$ & $0.73 *$ & 0.63 & 0.57 \\
\hline
\end{tabular}
A Year Ahead $\dagger$

1990-2010 e

2003-2010

(iv)

Energy

Crude Oil

0.64

$0.36^{*}$

$0.34 *$

Heating Oil

$0.78 *$

0.72

$0.38^{*}$

$0.39 *$

Natural Gas

0.74

0.74

0.57

0.63

Aluminum

0.76

0.58

0.62

Lead

0.80

0.83

0.43

0.46

Tin

0.88

0.56

0.55

Zinc

$0.73 *$

0.63

Notes: $\uparrow$ For commodities in the energy category, statistics are calculated for 12-month ahead futures. For metals, the statistics are for 15-month ahead forwards. For agricultural commodities, the statistics are for 8-month ahead futures. Samples begin in 1990 or as available.

* Indicates a statistically significant difference based on a Diebold-Mariano test. 
Table 4 : Relative Mean Squared Error of Futures Based Forecasts, Conditional On Spread Value of $\mathrm{F} / \mathrm{S}$

$$
\begin{array}{cccccc}
<0.85 & (0.85 \text { to } 0.95) & (0.95 \text { to } 1.05) & (1.05 \text { to } 1.15) & >1.15 & \text { Full Sample } \\
\text { (i) } & \text { (ii) } & \text { (iii) } & \text { (iv) } & \text { (v) } & \text { (vi) }
\end{array}
$$

\section{Energy}

Crude Oil

0.93

1.34

1.01

0.70

0.31

0.92

Heating Oil

0.44

1.37

1.00

0.75

0.51

0.92

Natural Gas $\quad 0.57$

0.94

1.01

0.99

0.76

0.86

Metals

Aluminum

NA

2.73

Copper

1.43

1.05

1

0.96

0.91

0.02

0.93

Lead

1.50

1.04

0.98

1.21

0.72

1.19

1.03

Tin

0.03

0.81

1

0.87

NA

1.08

Zinc

0.42

0.98

0.92

0.73

0.91

NA

1

1

Agricultural

Corn

0.10

0.85

0.98

1

NA

1.05

Cotton

0.40

0.71

1.06

0.76

NA

0.86

Coffee

0.47

0.80

1.02

1.16

0.67

0.77

Live Cattle

NA

0.23

Soybeans

0.32

1.42

1.10

1.08

0.97

0.97

1.50

0.60

0.93

1.55

5.24

1.59

0.94

0.81

NA

0.84

Wheat $\quad 0.45$

0.87

1.06

1.16

1.29

1.05

Notes: For commodities in the energy category, statistics are calculated for 12-month ahead futures. For metals, the statistics are for 15-month ahead forwards. For agricultural commodities, the statistics are for 8-month ahead futures. Samples begin in 1990 or as available. 
Table 5: Forecast Efficiency Regressions, One Year Ahead

\begin{tabular}{|c|c|c|c|c|c|c|}
\hline & \multicolumn{2}{|c|}{ Intercept, $\alpha$} & \multicolumn{3}{|c|}{ Slope, $\beta$} & \multirow{4}{*}{$\begin{array}{c}\text { Joint Test } \\
\alpha=0 \\
\text { and } \beta=1 \\
\text { (vi) }\end{array}$} \\
\hline & Point & T-Test & Point & T-Teșt & T-Teșt & \\
\hline & Estimate & $\alpha=0$ & Estimate & $\beta=0$ & $\beta=1$ & \\
\hline & & & (iii) & & & \\
\hline \multicolumn{7}{|l|}{ Energy } \\
\hline Crude Oil & 0.09 & 1.71 & 0.94 & 3.67 & -0.23 & 3.16 \\
\hline Heating Oil & 0.07 & 1.33 & 0.93 & 2.66 & -0.19 & 1.83 \\
\hline Natural Gas & 0.01 & 0.14 & 0.85 & 3.21 & -0.59 & 0.36 \\
\hline \multicolumn{7}{|l|}{ Metals } \\
\hline Aluminum & -0.02 & -0.26 & 1.19 & 1.19 & 0.19 & 0.07 \\
\hline Copper & 0.08 & 1.29 & 0.29 & 0.35 & -0.83 & 2.51 \\
\hline Lead & 0.06 & 0.81 & 0.39 & 0.63 & -0.97 & 1.06 \\
\hline Nickel & 0.08 & 0.88 & 0.79 & 1.22 & -0.33 & 1.02 \\
\hline Tin & 0.09 & 1.44 & -0.71 & -0.66 & -1.58 & 3.20 \\
\hline Zinc & 0 & -0.02 & 2.07 & 3.91 & 2.02 & 6.10 \\
\hline \multicolumn{7}{|c|}{ Agricultural } \\
\hline Corn & -0.08 & -2.03 & 1.14 & 4.49 & 0.55 & 4.16 \\
\hline Cotton & -0.07 & -1.8 & 0.8 & 3.82 & -0.95 & 7.23 \\
\hline Coffee & 0.02 & 0.24 & 0.69 & 2.74 & -1.23 & 1.61 \\
\hline Live Cattle & 0.01 & 1.01 & -0.06 & -0.22 & -3.69 & 23.77 \\
\hline Soybeans & 0.02 & 0.57 & 0.93 & 3.06 & -0.22 & 0.36 \\
\hline Wheat & 0.01 & 0.21 & 0.39 & 2.51 & -3.91 & 16.2 \\
\hline
\end{tabular}


Table 6 : Relative Mean Squared Error of Futures Based Forecasts to Risk-Premium-Corrected Forecasts

Three Months Ahead

Full Sample 2003-2010 Sample

(i)

\section{Energy}

Crude Oil

0.80

0.82

0.78

Natural Gas

Metals

Aluminum

Copper

Lead

Nickel

Tin

Zinc

\section{Agricultural}

Corn

Cotton

Coffee

Live Cattle

Soybeans

0.82

0.83

0.84

0.64

0.57

0.59

0.80

0.87

0.75

0.83

0.57

0.83 (ii)

0.80
0.91
1.02

0.80

0.80

0.87

0.71

0.48

0.65

0.84

0.97

0.57

0.85

0.51

0.70
A Year Ahead $\dagger$

Full Sample

(iii)

2003-2010 Sample

(iv)

$\begin{array}{ll}0.62 & 0.76 \\ 0.61 & 0.79 \\ 0.82 & 0.90\end{array}$

0.60

0.59

0.49

0.52

0.62

0.70

0.08

0.64

0.41

0.37

0.30

0.27

$\begin{array}{ll}0.81 & 0.74\end{array}$

$0.95 \quad 0.83$

$0.54 \quad 0.54$

$0.24 \quad 0.24$

$0.58 \quad 0.60$

0.84
0.80

Notes: $†$ The year ahead forecast is based on the appropriate and available futures contract. For commodities in the energy category, statistics are calculated for 12-month ahead futures. For metals, the statistics are for 15-month ahead forwards. For agricultural commodities, the statistics are for 8-month ahead futures. Samples begin in 1990 or as available. 
Figure 1

Relationship Between Future/Spot Prices and Inventories for Copper

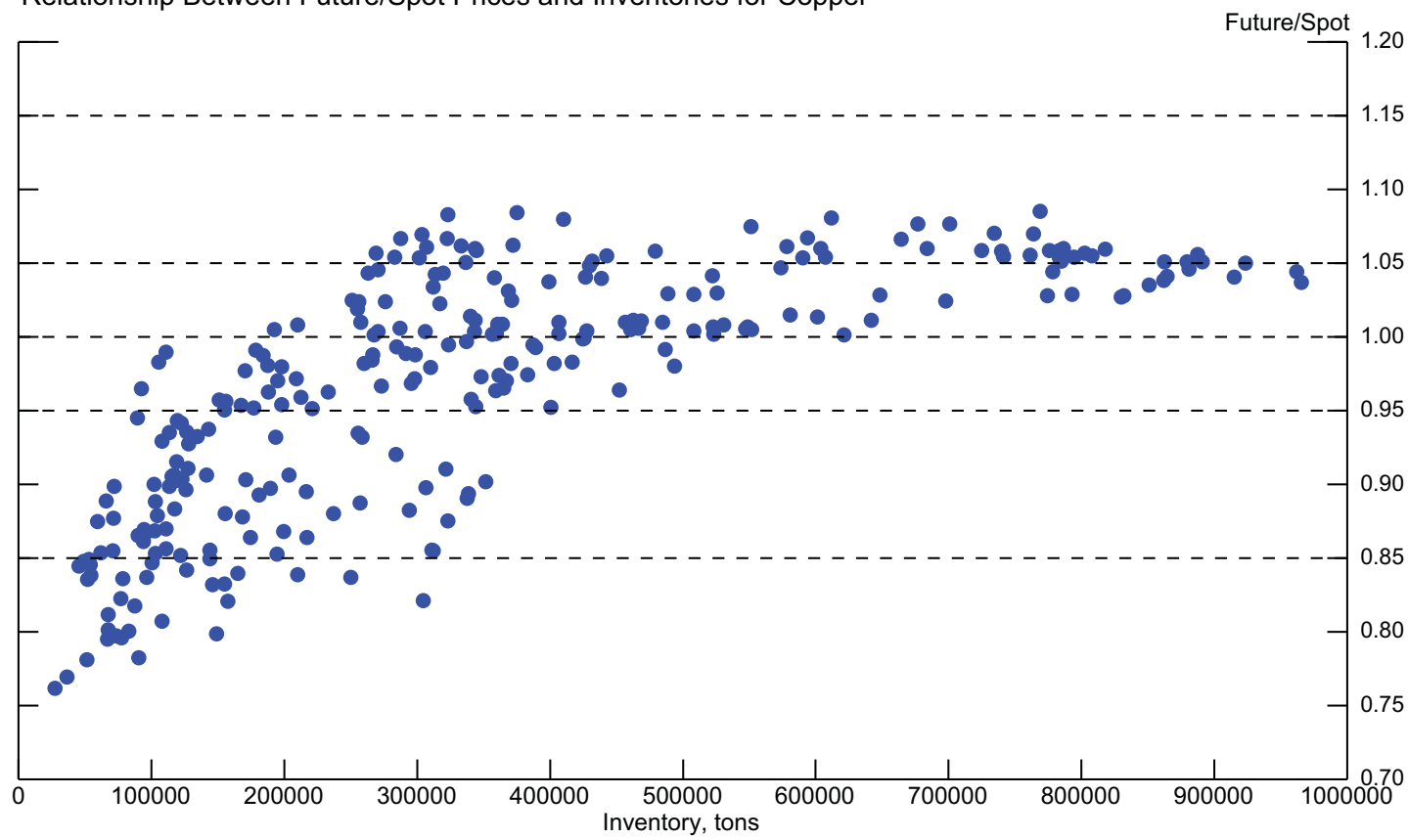

All data are from the London Metal Exchange. Sample period is 1990-2011.

Figure 2

Relationship Between Future/Spot Prices and Inventories for Oil

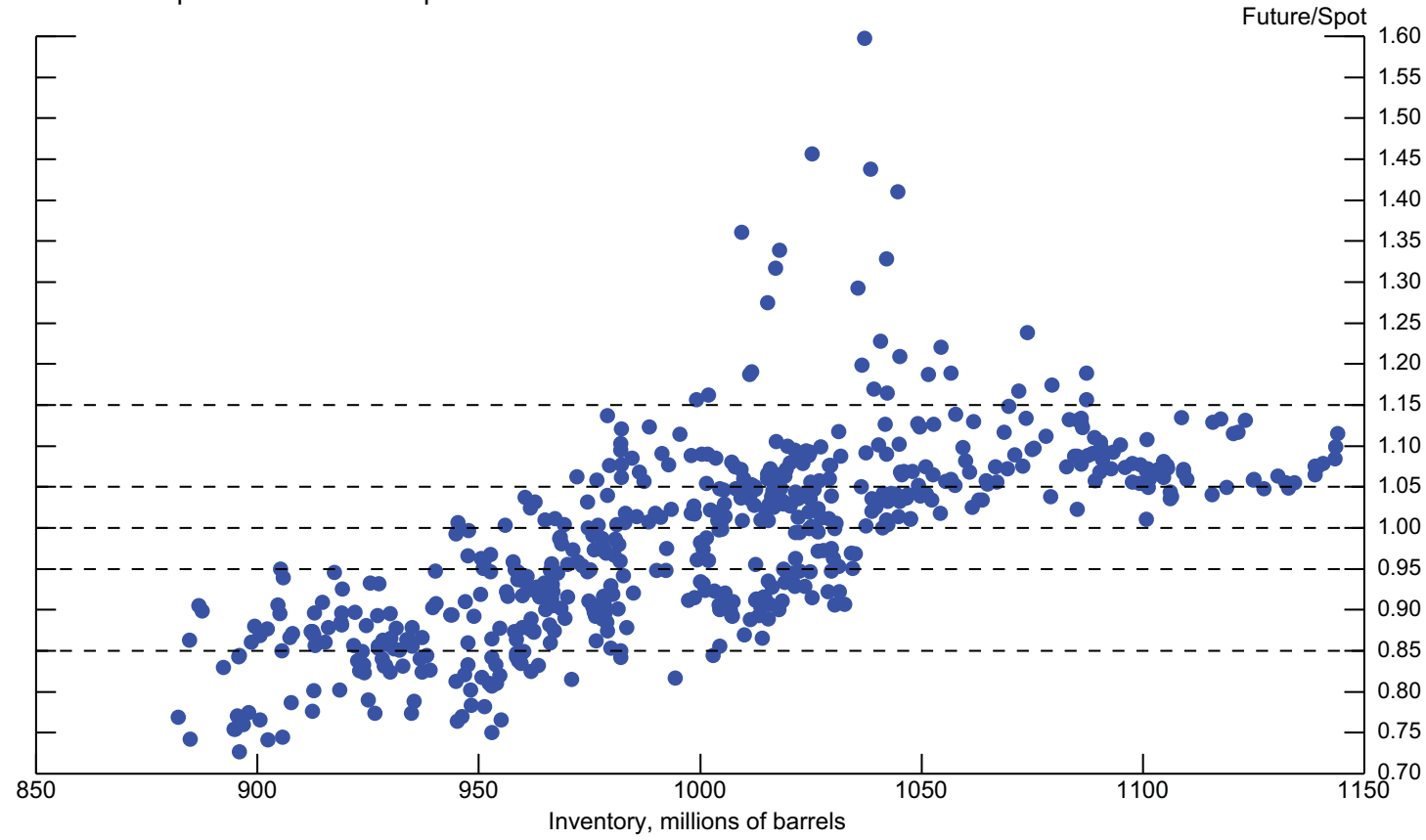

Prices are for WTI crude oil. Inventories are U.S. stocks of crude oil and petroleum products. Sample period is 1990-2011. 
Figure 3

Relative MSE of Futures Versus Random Walk Forecasts Evaluated Over a Rolling Eight Year Window

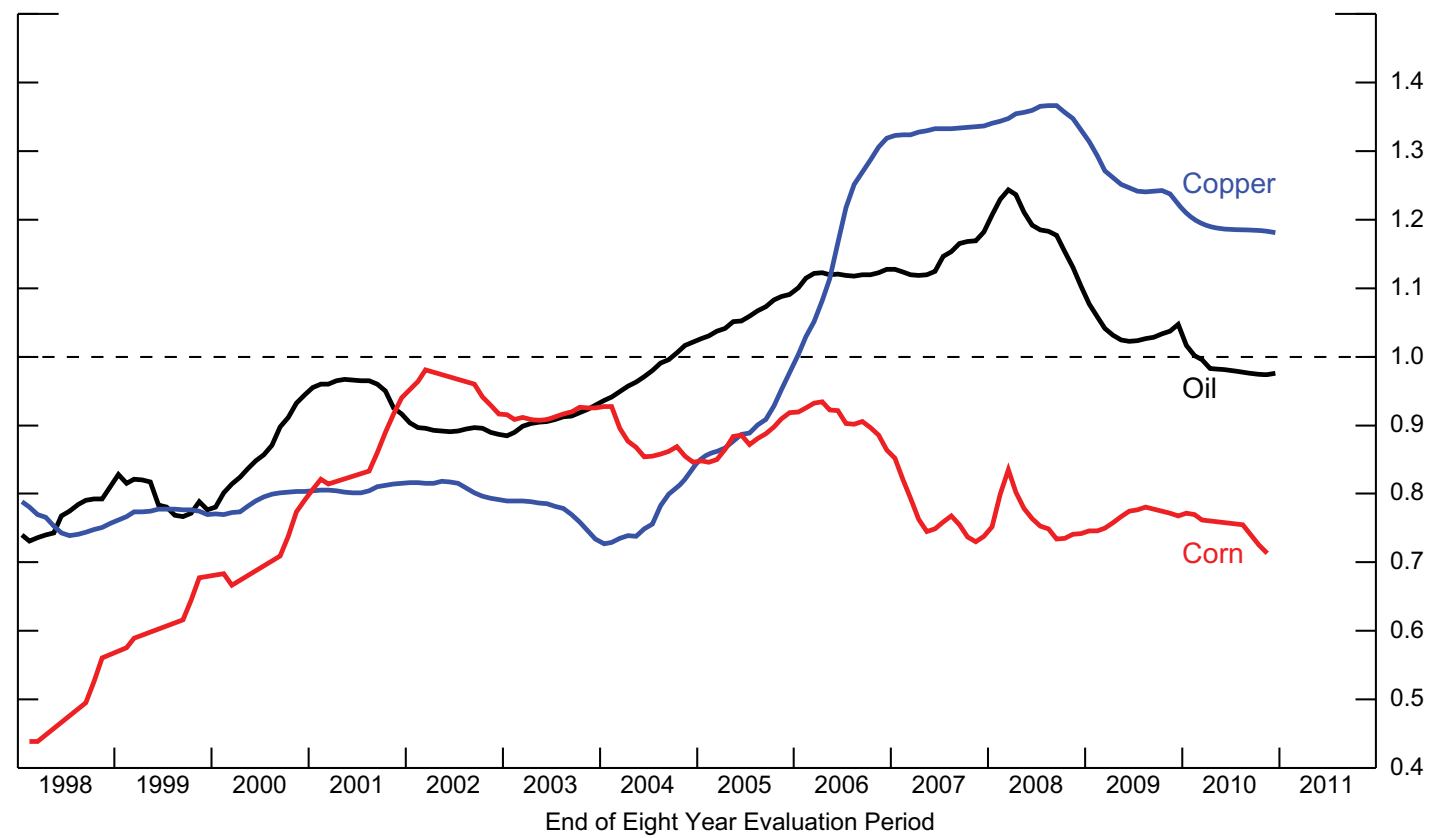

For copper and oil, the evaluated forecasts are at the 12-month horizon. For corn, the evaluated forecasts are at the 8-month horizon.

Figure 4

Relationship Between Future/Spot Prices and Forecasting Accuracy for Oil

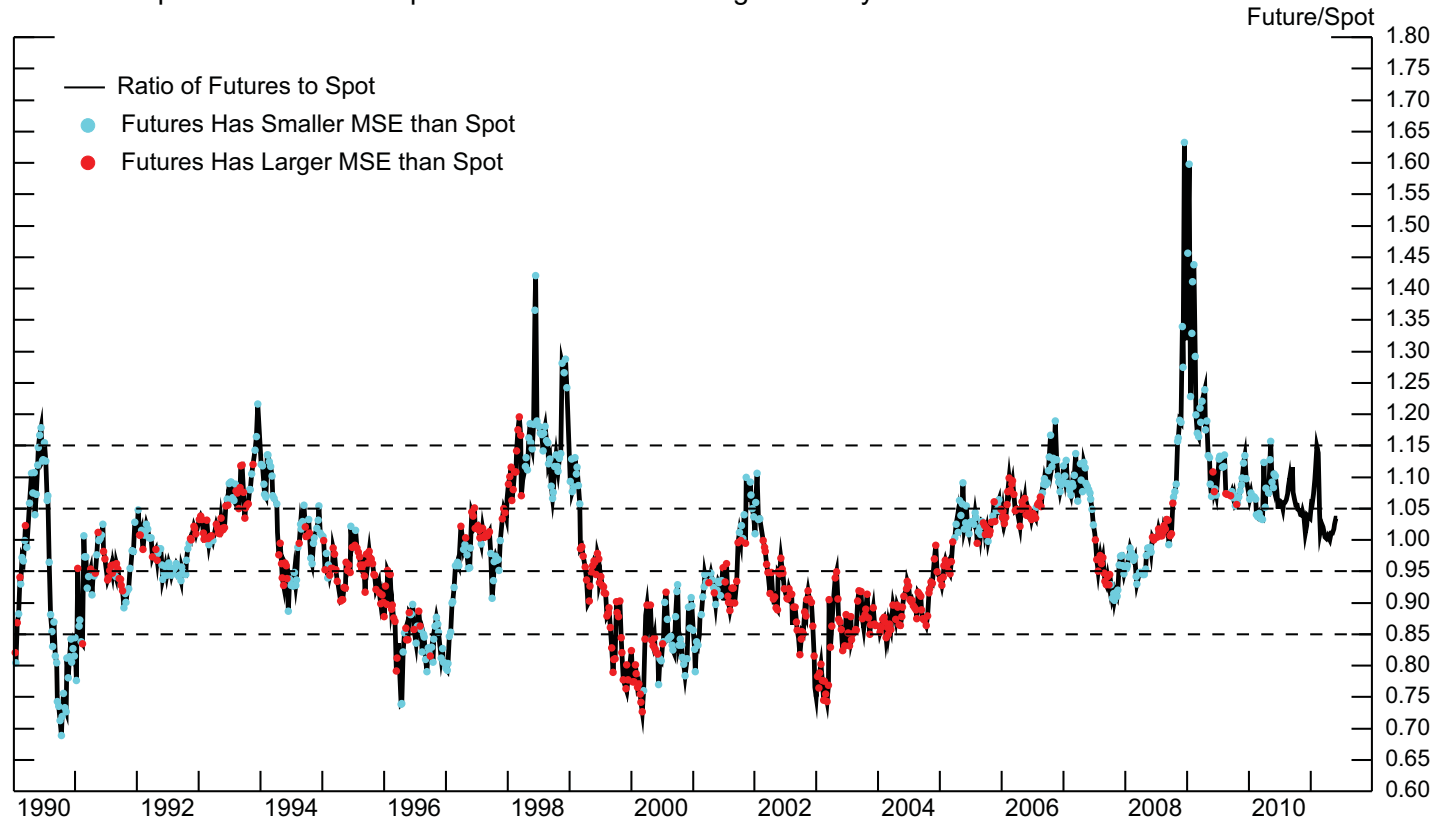




\section{Net Long Futures Positions of Producers/Users}

Copper

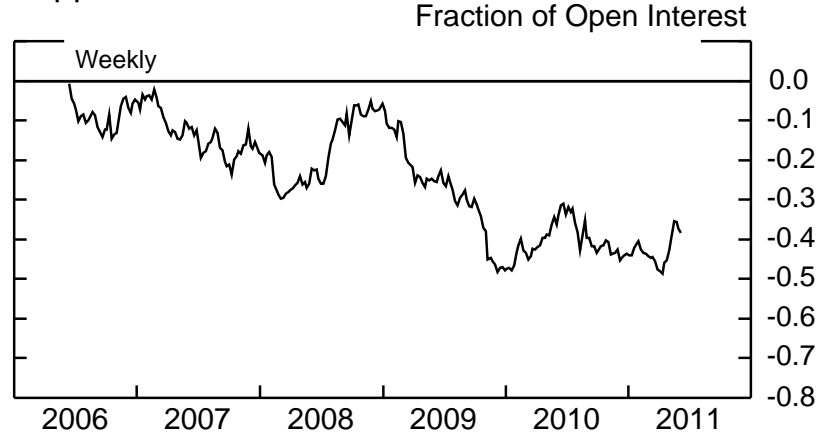

Natural Gas

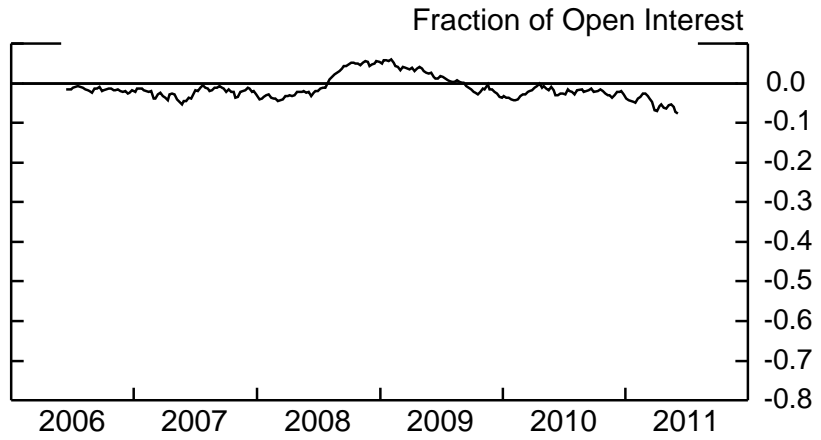

WTI Crude Oil

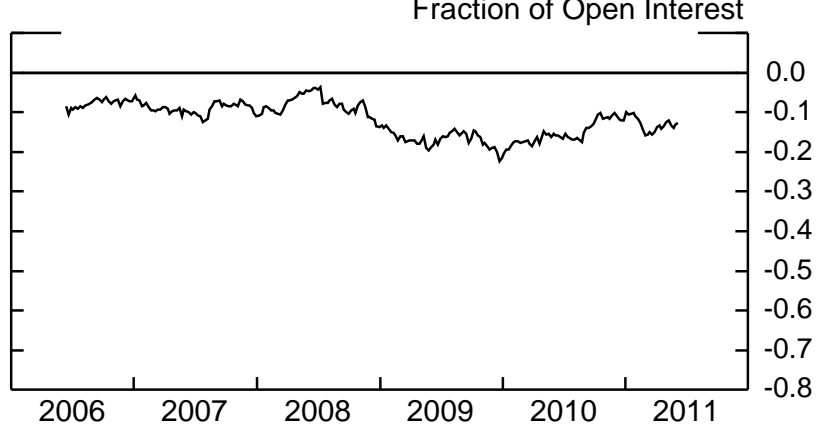

Cotton

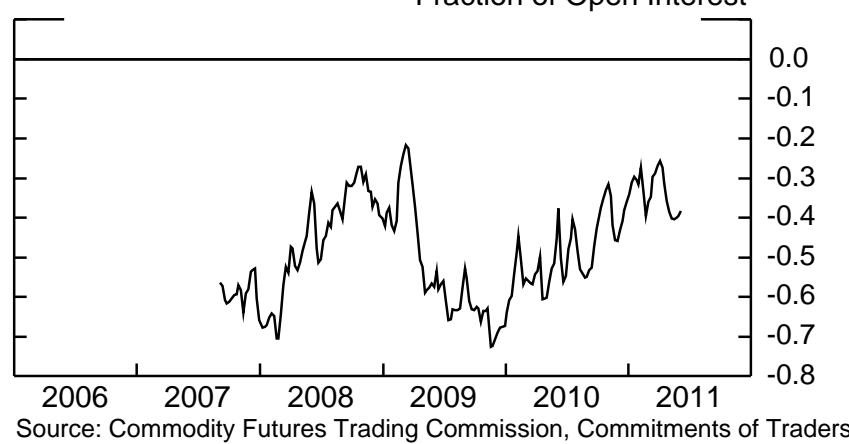

Corn

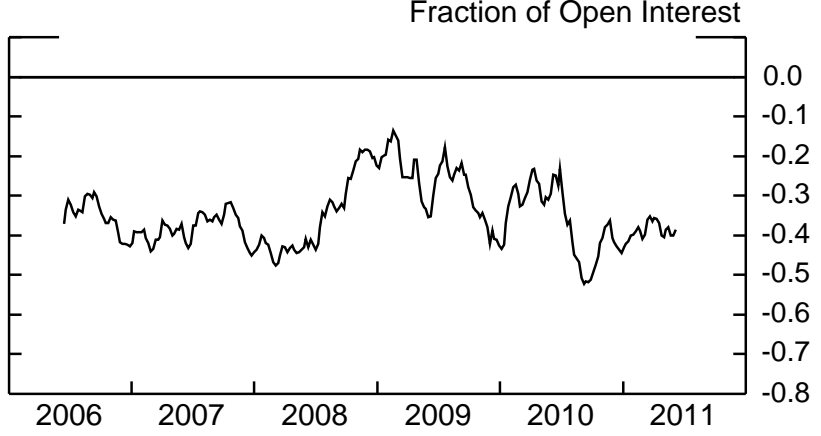

Soybeans

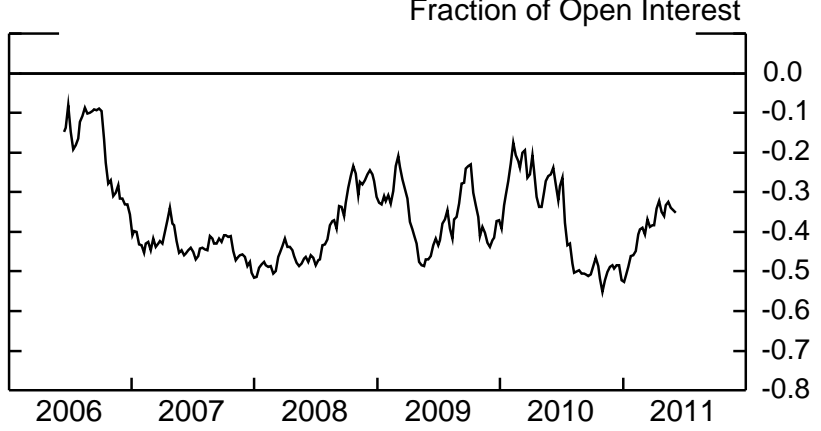

Wheat (CBOT)

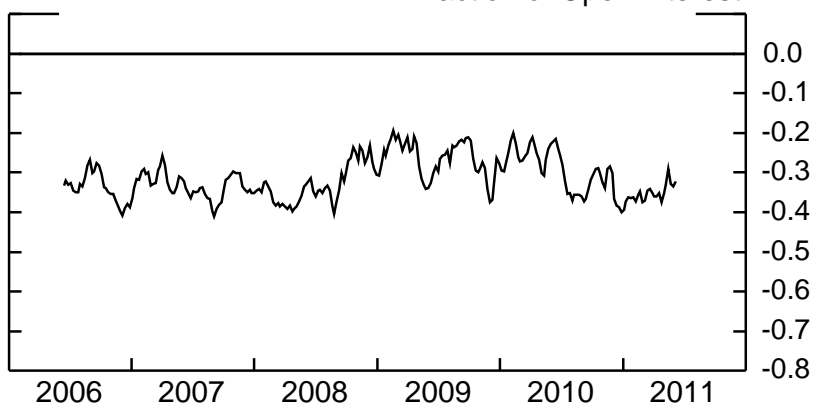

Sugar

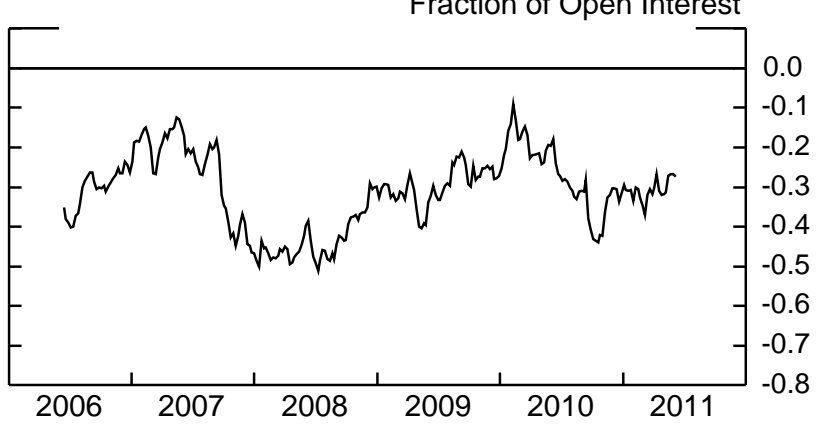

